\title{
Investigation of silver and iodine transport through silicon carbide layers prepared for nuclear fuel element cladding
}

\author{
E. Friedland ${ }^{1, *}$, N.G. van der Berg ${ }^{1}$, J.B. Malherbe ${ }^{1}$, J.J. Hancke ${ }^{2}$, J. Barry ${ }^{2}$, E.Wendler ${ }^{3}$, \\ W.Wesch ${ }^{3}$ \\ ${ }^{1}$ Physics Department, University of Pretoria, Pretoria, South Africa \\ ${ }^{2}$ PBMR (Pty) Ltd., Pretoria, South Africa \\ ${ }^{3}$ Institut für Festkörperphysik, Friedrich-Schiller-Universität, Jena, Germany
}

\begin{abstract}
.
Transport of silver and iodine through polycrystalline SiC layers produced by PBMR (Pty) Ltd for cladding of TRISO fuel kernels was investigated using Rutherford backscattering analysis and electron microscopy. Fluences of $2 \times 10^{16} \mathrm{Ag}^{+} \mathrm{cm}^{-2}$ and $1 \times 10^{16} \mathrm{I}^{+} \mathrm{cm}^{-2}$ were implanted at room temperature, $350{ }^{\circ} \mathrm{C}$ and $600{ }^{\circ} \mathrm{C}$ with an energy of $360 \mathrm{keV}$, producing an atomic density of approximately $1.5 \%$ at the projected ranges of about $100 \mathrm{~nm}$. The broadening of the implantation profiles and the loss of diffusors through the front surface during vacuum annealing at temperatures up to $1400{ }^{\circ} \mathrm{C}$ was determined. The results for room temperature implantations point to completely different transport mechanisms for silver and iodine in highly disordered silicon carbide. However, similar results are obtained for high temperature implantations, although iodine transport is much stronger influenced by lattice defects than is the case for silver. For both diffusors transport in well annealed samples can be described by Fickian grain boundary diffusion with no abnormal loss through the surface as would be expected from the presence of nano-pores and/or micro-cracks. At $1100{ }^{\circ} \mathrm{C}$ diffusion coefficients for silver and iodine are below our detection limit of $10^{-21} \mathrm{~m}^{2} \mathrm{~s}^{-1}$, while they increase into the $10^{-20} \mathrm{~m}^{2} \mathrm{~s}^{-1}$ range at $1300{ }^{\circ} \mathrm{C}$.
\end{abstract}

\section{Introduction}

Fuel particles of modern high-temperature nuclear reactors (HTR's) are encapsulated by CVD-layers which serve as barriers to prevent fission product release. Recent reactor designs generally make use of fuel kernels surrounded by four successive layers of low-density pyrocarbon, high-density pyrocarbon, silicon carbide and high-density pyrocarbon, with silicon carbide being the main barrier for the metallic species. These so-called TRISO fuel particles retain quite effectively most of the important fission products like cesium, iodine, xenon and krypton up to temperatures of $1000{ }^{\circ} \mathrm{C}$, but the release of silver seems to present a major problem. Despite the low fission yield of the stable ${ }^{109} \mathrm{Ag}\left(0.03 \%\right.$ for $\left.{ }^{235} \mathrm{U}\right)$ and its low conversion rate of $0.1 \%$ to ${ }^{110 \mathrm{~m}} \mathrm{Ag}$ by neutron capture, the latter is considered as one of the key fission products. The reason is the high $\gamma$-ray dose rate of ${ }^{110 \mathrm{~m}} \mathrm{Ag}$ with a relatively long half-life of 253 days. Release studies from batches of fuel particles or even entire fuel elements have produced largely differing results concerning magnitude and temperature dependence of silver transport through the particle coatings. While results from earlier investigations could be interpreted as a diffusion process governed by an Arrhenius type temperature dependence [1,2], a later study found a transport behaviour indicating a flow mechanism through nano-cracks [3]. However, a direct comparison of these results makes not much sense, as they were obtained with samples from completely different production sources. In the first case fuel particles from the Jülich Arbeitsgemeinschaft Versuchsreaktor (AVR) were investigated, while in

\footnotetext{
*Corresponding author. E mail: erich.friedland@up.ac.za
} 
the second study Coorstek CVD wafers and CVD-diffusion couples prepared at the Massachusetts Institute of Technology were analyzed. Most likely the apparently contradictory results can be explained by micro-structural differences of the investigated samples.

More recently our group measured silver diffusion coefficients in single and polycrystalline silicon carbide wafers obtained from Intrinsic Semiconductors ${ }^{\circledR}$ and Valley Design Corporation $^{\circledR}$ respectively [4]. In that study the broadening of silver implantation profiles during prolonged isochronal annealing has been determined from which diffusion coefficients were extracted. In all samples the first measurable broadening was observed at $1200{ }^{\circ} \mathrm{C}$ after a first annealing step of 10 hours. Longer annealing times and temperatures up to $1600{ }^{\circ} \mathrm{C}$ yielded no further broadening in the single crystalline samples, while it was significantly reduced in the polycrystalline samples. This enhanced initial diffusion is obviously due to implantation induced radiation damage, which was removed during the first annealing step. In polycrystalline silicon carbide diffusion coefficients varied between approximately $1.4 \times 10^{-20} \mathrm{~m}^{2} \mathrm{~s}^{-1}$ at $1200{ }^{\circ} \mathrm{C}$ and $1.5 \times 10^{-19} \mathrm{~m}^{2} \mathrm{~s}^{-1}$ at $1400{ }^{\circ} \mathrm{C}$ and exhibited Fickian diffusion characteristics. These values are far too small to explain the relatively large silver losses observed with the above-mentioned fuel release studies. No diffusion in the single crystalline samples was observed up to $1600{ }^{\circ} \mathrm{C}$. Instead a shift of the profile towards the surface accompanied by a simultaneous loss of silver occurred above $1450{ }^{\circ} \mathrm{C}$. This is in agreement with the observations of ref. [5], who found no evidence of silver diffusion in single crystalline $\mathrm{SiC}$ at temperatures up to $1300{ }^{\circ} \mathrm{C}$ but a tendency of the silver to shift towards the surface at higher temperatures. According to our measurements the silver diffusion coefficient in $6 \mathrm{H}-\mathrm{SiC}$ at $1300{ }^{\circ} \mathrm{C}$ is below $10^{-21} \mathrm{~m}^{2} \mathrm{~s}^{-1}$, from which one can conclude that the observed diffusion in the polycrystalline samples is mainly due to grain boundary diffusion while volume diffusion can be neglected.

In a similar study on iodine transport in room temperature implanted silicon carbide we obtained results, which cannot be explained by Fickian diffusion [6]. Radio-active iodine isotopes, especially ${ }^{129} \mathrm{I}\left(\mathrm{T}_{1 / 2}=15.7 \times 10^{6} \mathrm{y}\right)$ and ${ }^{131} \mathrm{I}\left(\mathrm{T}_{1 / 2}=8 \mathrm{~d}\right)$, are important fission products and of radio-ecological relevance because of their accumulation in the thyroid gland with a biological half-life of approximately 140 days. Up to $1100^{\circ} \mathrm{C}$ extremely low diffusion coefficients of less than $10^{-21} \mathrm{~m}^{2} \mathrm{~s}^{-1}$ were observed, which is in agreement with the results of ref. [7], who found no diffusion in a similar experiment after annealing at $1000{ }^{\circ} \mathrm{C}$ for 30 minutes. However, at $1200{ }^{\circ} \mathrm{C}$ diffusion increased by almost two orders of magnitude, while very little iodine was lost through the surface. This is indicative of a different transport process presumably related to chemical reactions between iodine and the highly disordered silicon carbide in this temperature region. Electron microscopic investigations reveal a drastic change of the surface topography between $1100{ }^{\circ} \mathrm{C}$ and $1200^{\circ} \mathrm{C}$, which is not observed with un-implanted SiC wafers at even much higher temperatures.

Currently design studies for high-temperature nuclear reactors operating at temperatures significantly above $1000{ }^{\circ} \mathrm{C}$ are under way to enhance their efficiency, especially in view of process heat applications for hydrogen generation. It therefore becomes necessary to investigate transport behaviour of fission products through fuel claddings at temperatures above 1000 ${ }^{\circ} \mathrm{C}$, where little reliable information is available. The results obtained from commercial wafers are not necessarily representative as the multiple and sometimes violent collisions between fuel kernels during the deposition of the cladding material might introduce additional pathways due to mechanical damage. In this study we investigate silver and iodine diffusion through silicon 
carbide layers produced by PBMR (Pty) Ltd in a coater, operated under similar conditions as used for coating dummy fuel kernels consisting of zirconium oxide. The results are compared with our results obtained with polycrystalline commercial wafers $[4,6]$. Furthermore diffusion of iodine in high temperature implants was investigated to obtained information on transport mechanisms above $1000{ }^{\circ} \mathrm{C}$ in relatively intact crystal lattices, which is not available in the literature.

\section{Experimental Method}

The deposition of $\mathrm{SiC}$ on substrates of commercial polycrystalline $\mathrm{SiC}$ wafers was done in the Research Coater Facility of PBMR, Pelindaba, under similar conditions as used for the production of TRISO particles. This facility consists of a chemical vapour deposition (CVD) coater that takes a charge of up to $1 \mathrm{~kg}$ of kernels. The initial diameters of the particles present while the wafers were being coated were around $710 \mu \mathrm{m}$. A charge of $900 \mathrm{~g}$ of particles was used in this case. A graphite shaft with nine horizontal rods was placed in a fixed upright position in the centre of the reaction tube inside the coater (Fig. 1). The wafers were secured in slots between the horizontal rods. The CVD deposition was carried out at a temperature of around $1500{ }^{\circ} \mathrm{C}$, as measured on the outside of the reaction tube. A mixture of methyl trichlorosilane and hydrogen was constantly fed into the bottom of the reaction tube causing the particles to fluidize and $\mathrm{SiC}$ to be deposited on the surface of the particles and the wafers. After the coating had been completed and the coater had cooled down, the wafers were extracted and used without any further treatment. The microstructure of the deposited $\mathrm{SiC}$ layer was investigated by scanning electron microscopy (SEM) employing Jeol 5800 and Zeiss Ultra 55 instruments.

Into the coated wafers $360 \mathrm{keV}$ ions were implanted at temperatures ranging from room temperature (RT) to $600{ }^{\circ} \mathrm{C}$ with a fluence of either $2 \times 10^{16} \mathrm{Ag}^{+} \mathrm{cm}^{-2}$ or $1 \times 10^{16} \mathrm{I}^{+} \mathrm{cm}^{-2}$ and a flux not exceeding $10^{13} \mathrm{~cm}^{-2} \mathrm{~s}^{-1}$. High implantation temperatures were chosen to reduce irradiation damage. According to TRIM simulations [9] the above fluences introduce displacement damages of $\sim 50 \mathrm{dpa}$ at $80 \mathrm{~nm}$ and $\sim 30 \mathrm{dpa}$ at $70 \mathrm{~nm}$ respectively. $\alpha-$ Particle channeling in single crystalline samples reveals complete amorphization of the surface regions up to depths of $\sim 260 \mathrm{~nm}$ and $\sim 225 \mathrm{~nm}$ for the silver and iodine implantations at $\mathrm{RT}$ in $6 \mathrm{H}-\mathrm{SiC}$. It also shows that the well-known radiation hardness of $\mathrm{SiC}$ above $300{ }^{\circ} \mathrm{C}$ [8] leaves the crystal structure intact if implanted above that temperature, although high densities of extended defects are observed.

The implanted wafers were vacuum annealed in a computer controlled Webb Red Devil graphite furnace for periods ranging from 5 to 60 hours. Isochronal as well as isothermal annealing studies at temperatures up to $1400{ }^{\circ} \mathrm{C}$ were done. Depth profiles of the implanted ions before and after annealing were obtained by Rutherford backscattering spectrometry (RBS) at room temperature using $\alpha$-particles with energies between 1.4 and $1.8 \mathrm{MeV}$. The analyzing particle beam was collimated at a spot of $1 \mathrm{~mm}$ diameter and the current of approximately 20 $\mathrm{nA}$ was measured directly on the target. A ring-shaped electrode in front of the target was kept at a negative potential of $200 \mathrm{~V}$ to suppress secondary electrons. Backscattered particles were observed at $165^{\circ}$ by a surface barrier detector telescope with an acceptance angle of $2^{\circ}$. Sufficient counting statistics was obtained by collecting an integrated charge of $8 \mu \mathrm{C}$ at $1.4 \mathrm{MeV}$ 
and $9 \mu \mathrm{C}$ at $1.8 \mathrm{MeV}$. Energy calibration was obtained from the observed spectral shift of the silicon edge between the two beam energies. Typical RBS-spectra are shown in Fig. 2. Energies of the backscattered particles are converted to a depth scale by using the energy loss data of Ziegler [10], assuming a density of $3.21 \mathrm{~g} \mathrm{~cm}^{-3}$ [11]. Depth resolution near the surface is limited by the system's energy resolution of $12 \mathrm{keV}$ to approximately $15 \mathrm{~nm}$ for scattering from the implanted atoms. Because of energy straggling this value increases to almost $20 \mathrm{~nm}$ at a depth of $100 \mathrm{~nm}$.

\section{Results}

SEM images of the deposited layer with a thickness of approximately $10 \mu \mathrm{m}$ are shown in Fig. 3. The material consists of a network of relatively large crystallites with a rudimentary columnar structure along the growth direction, which is similar to that of the silicon carbide layer deposited on PBMR fuel particles [12]. The crystallites exhibit numerous stacking faults and twins. This columnar characteristic is much clearer developed in the commercial wafers studied earlier [4]. As-implanted depth profiles are relatively well described by simulations obtained with the TRIM-98 code assuming displacement energies of $35 \mathrm{eV}$ and $20 \mathrm{eV}$ for the silicon and carbon atoms respectively [13]. Experimentally observed projected ranges of 103 $\mathrm{nm}$ for silver and $98 \mathrm{~nm}$ for iodine are in good agreement with the theoretical estimates of 107 $\mathrm{nm}$ and $100 \mathrm{~nm}$ respectively. Range straggling, however, is about 50\% larger than predicted for the iodine implantations at room temperature and almost $70 \%$ larger for those at $600{ }^{\circ} \mathrm{C}$. This points to strong temperature dependences of irradiation induced diffusion during implantations. Although the higher distribution moments, especially the skewness $\gamma$, differ somewhat from the Gaussian values, the depth profiles can at a first approximation still be considered as almost normal distributions. Fick's diffusion equation for the dilute limit leads to a particularly simple solution if the original profile at time $t_{0}=0$ can be described by a Gaussian distribution [14]. In that case the concentration profile after annealing for a time $t$ stays a normal distribution in an infinite medium and is given by

$$
C(x, t)=K[\pi D t]^{-1 / 2} \exp \left(-x^{2} / 4 D t\right) .
$$

In this equation $K$ is an adjustable constant, while the position of the maximum concentration is unchanged at $x=0$. Defining the profile width $W(t)$ as the full width at half maximum (FWHM), the following relationship between the final and original widths holds:

$$
[W(t)]^{2}=4 D t \ln (2)+[W(0)]^{2} .
$$

Hence, the diffusion coefficient $D$ is directly obtained from the slope of a plot of $[W(t)]^{2}$ versus annealing time at constant temperature.

Fig. 4 displays depth profiles of silver before and after isochronal annealing for samples implanted at $600{ }^{\circ} \mathrm{C}$. Iodine depth profiles for room and high temperature implants are shown in Fig. 5. An increasing asymmetry is observed at higher annealing temperatures when the diffusing atoms reach the surface. In order to exclude this surface effect from the analysis only the distribution for depths of $d>60 \mathrm{~nm}$ is fitted to a Gaussian function. As the shapes of the 
implantation profiles are approximately Gaussian in the peak region, this additional approximation should still allow an analysis in terms of the procedure discussed above without introducing too large uncertainties. In the samples implanted at room temperature the profile widths of silver increase continuously with temperature as is expected for Fickian diffusion, while a completely different picture emerges from the annealing results of the iodine implants. The observed sudden and extremely large increase of iodine transport above $1200{ }^{\circ} \mathrm{C}$ is difficult to explain by normal diffusion but indicates that a different transport mechanism becomes effective at this temperature. In contrast to this, no abnormal behaviour is visible in the high temperature implants, where up to $1300{ }^{\circ} \mathrm{C}$ iodine diffusion is barely visible after annealing for 5 hours.

Isothermal annealing curves for silver are displayed in Fig. 6 and the equivalent data for the iodine implants are shown in Fig. 7 and Fig. 8. Diffusion coefficients were determined from the slopes, excluding the initially enhanced diffusion rate where radiation damage effects are present. The fractions of retained silver or iodine after each annealing cycle depicted in Fig. 9 were directly determined from the RBS spectra by normalizing the integral of the implantation peak to the counts per unit depth near the silicon edge.

\section{Discussion}

\subsection{Silver transport}

During isochronal annealing from $900{ }^{\circ} \mathrm{C}$ up to $1400{ }^{\circ} \mathrm{C}$ for 5 hours each at temperature intervals of $100{ }^{\circ} \mathrm{C}$, profile broadening was first observed at $1200{ }^{\circ} \mathrm{C}$. Silver loss of about $5 \%$ was detected at $1300{ }^{\circ} \mathrm{C}$, while $13 \%$ was lost at $1400{ }^{\circ} \mathrm{C}$. All isothermal annealing curves display an initial broadening, which is significantly larger than found at subsequent annealing steps. A similar observation was also made for commercial polycrystalline and single crystalline samples implanted at $350{ }^{\circ} \mathrm{C}$ and RT respectively [4]. This phenomenon has been interpreted as enhanced diffusion in the initially highly damaged lattice structure, which anneals out during the first annealing cycle above $1000{ }^{\circ} \mathrm{C}$. A reduced but linear profile broadening is observed after that first cycle, from which one can conclude that Fickian diffusion conditions prevail after the initial annealing step. The diffusion coefficients obtained from fitting the experimental data to a straight line yields the following values for silver:

$$
\begin{aligned}
& \mathrm{D}_{1200}=(4.7 \pm 0.5) \times 10^{-21} \mathrm{~m}^{2} \mathrm{~s}^{-1} \\
& \mathrm{D}_{1300}=(1.5 \pm 0.4) \times 10^{-20} \mathrm{~m}^{2} \mathrm{~s}^{-1} \\
& \mathrm{D}_{1400}=(1.2 \pm 0.2) \times 10^{-19} \mathrm{~m}^{2} \mathrm{~s}^{-1}
\end{aligned}
$$

Compared with the commercial CVD samples the observed diffusion coefficients are almost $50 \%$ smaller, which is still a reasonable agreement if one takes into account that grain boundary distribution in the surface region will play a decisive role. The results can also be reconciled with those of ref. [15] who found no diffusion in a similar experiment after annealing at $1180{ }^{\circ} \mathrm{C}$ for 30 minutes. According to the above results the diffusion coefficient at that temperature is of the order of $10^{-21} \mathrm{~m}^{2} \mathrm{~s}^{-1}$ and the expected profile broadening after such a short annealing time would be difficult to detect by RBS analysis. Assuming Arrhenius type tempera- 
ture dependence, a theoretical fit of the experimental data yielded the following values for the frequency factor and activation energy:

$$
\begin{gathered}
\mathrm{D}_{\mathrm{o}}=(2.4 \pm 0.3) \times 10^{-9} \mathrm{~m}^{2} \mathrm{~s}^{-1} \\
\mathrm{E}_{\mathrm{a}}=(5.5 \pm 0.5) \times 10^{-19} \mathrm{~J} .
\end{gathered}
$$

These results are plotted in Fig. 10 together with the results obtained previously for the commercial CVD samples [4]. The diffusion coefficients compare quite well, while the activation energy is approximately $20 \%$ higher. In view of the extremely low upper limit for the diffusion coefficient in defect-free single crystalline silicon carbide $[4,16]$, the diffusion can almost entirely be associated with grain boundary diffusion. This is also in agreement with an $a b$ initio calculation [17], from which the volume diffusion coefficient for silver at $1300{ }^{\circ} \mathrm{C}$ is estimated to be $3.6 \times 10^{-33} \mathrm{~m}^{2} \mathrm{~s}^{-1}$. A rough estimate from Fig. 2 of the relatively small fraction of grain boundary area exposed at the surface shows that grain boundary diffusion must be many orders of magnitude larger than volume diffusion. The quoted statistical errors are obtained for a particular sample. As the diffusion depends on the random distribution of grain sizes, differences between individual samples can be significantly larger. The observed silver loss as a function of annealing time is reconcilable with the increasingly larger fraction of the broadened distribution reaching the surface. Our results are in variance with the findings of ref. [16], who observed no sign of silver migration via either inter- or intra-granular paths.

As discussed in the introduction previously published silver diffusion results $[1,3]$ are based on indirect evidence of silver release studies from batches of fuel elements, which vary widely because of completely different production processes. Most of the reported silver loss is probably due to mechanical defects of the claddings and not a result of a diffusion process. These results can therefore not be compared with our results obtained by direct depth profile measurements.

\subsection{Iodine transport}

Room temperature implanted samples were subjected to isochronal annealing cycles of 5 hours each, starting at $900{ }^{\circ} \mathrm{C}$ and increasing the temperature between each cycle by $100{ }^{\circ} \mathrm{C}$ up to $1300{ }^{\circ} \mathrm{C}$. Single crystal channeling analysis [6] revealed complete disorder probably leading to amorphization up to a depth of approximately $220 \mathrm{~nm}$, which epitaxially re-grows from the bulk up to a depth of approximately $110 \mathrm{~nm}$ during the above heat treatment. Iodine profiles are shown in Fig. 5 after subsequent annealing at $1000{ }^{\circ} \mathrm{C}, 1200{ }^{\circ} \mathrm{C}$ and $1300{ }^{\circ} \mathrm{C}$. At $1000{ }^{\circ} \mathrm{C}$ little change was observed relative to the as-implanted sample after 5 hours annealing. The first measurable broadening of the implantation profile was observed at $1200^{\circ} \mathrm{C}$. As iodine transport becomes observable between $1100{ }^{\circ} \mathrm{C}$ and $1200{ }^{\circ} \mathrm{C}$, isothermal annealing studies were performed at these two temperatures. The slopes of the annealing curves at $1100{ }^{\circ} \mathrm{C}$ and $1200{ }^{\circ} \mathrm{C}$ displayed in Fig. 7 are somewhat larger than those observed with the commercial samples [6] but still in qualitative agreement with them. At $1100^{\circ} \mathrm{C}$ a diffusion coefficient of $(1.8 \pm 1.0) \times 10^{-21} \mathrm{~m}^{2} \mathrm{~s}^{-1}$ is obtained from the slope, while at $1200^{\circ} \mathrm{C}$ a sudden increase of almost two orders of magnitude takes place, from which an effective diffusion coefficient of $(0.65 \pm 0.07) \times 10^{-19} \mathrm{~m}^{2} \mathrm{~s}^{-1}$ is calculated. 
At $1100{ }^{\circ} \mathrm{C}$ no iodine loss is observed after the full annealing time of 60 hours. In Fig. 9 iodine retention at $1200{ }^{\circ} \mathrm{C}$ is plotted as a function of annealing time compared with the values for the commercial samples studied previously [6]. Iodine loss becomes apparent after 15 hours and reaches a value of about $20 \%$ after 60 hours. This loss is significantly larger than obtained for the commercial samples but still smaller than expected from the extreme broadening of the iodine profile, which should expose a much larger portion of iodine to the surface.

Samples implanted at $600{ }^{\circ} \mathrm{C}$ reveal a completely different behaviour as shown in Fig. 8. The slopes of the isothermal annealing curves show initially an enhanced broadening rate of the depth distributions, which is significantly reduced after prolonged annealing. This indicates that extended defects still present after hot implantations have a significant influence on the diffusion rate. During annealing these defects are further reduced or modified to form structures less favourable for iodine diffusion. At $1200{ }^{\circ} \mathrm{C}$ this transition is reached at a time somewhere between 5 and 30 hours, while at $1300{ }^{\circ} \mathrm{C}$ this state is already obtained before 5 hours. The final slopes for the two annealing temperatures are nearly identical within experimental error. An average diffusion coefficient of $(6 \pm 2) 10^{-20} \mathrm{~m}^{2} \mathrm{~s}^{-1}$ is extracted for this temperature region. Less than $10 \%$ of the iodine is lost after 60 hours annealing at $1300{ }^{\circ} \mathrm{C}$, of which most occurs already at relatively low temperatures as is evident from Fig. 5. Iodine diffusion is, like that of silver, mainly due to grain boundary diffusion, as the volume diffusion coefficient at $1300{ }^{\circ} \mathrm{C}$ is less than $3 \times 10^{-21} \mathrm{~m}^{2} \mathrm{~s}^{-1}$ [18].

Fig. 11 and Fig. 12 are SEM images of samples implanted at room temperature and at $600{ }^{\circ} \mathrm{C}$ respectively after annealing for 5 hours at $130{ }^{\circ} \mathrm{C}$. They reveal dramatic topographical modifications in the case of the room temperature implants. Numerous small facetted crystals have grown on the surface with deep cavities between them, which increase in depth and size during further annealing. A similar change of topography at a smaller rate is also observed after annealing at $1200{ }^{\circ} \mathrm{C}$. The area covered by these cavities and their average depth is relatively large and hence a significant fraction of the implanted iodine should have been exposed to the sample surface, where it could have evaporated. This is obviously not the case, which points to a chemical reaction binding the iodine to the silicon carbide lattice. The observed surface structure after prolonged high temperature annealing is very similar to those of iodine implanted single crystalline samples [6]. In contrast to this behaviour the high temperature implants exhibit the original polycrystalline structure, which does not change even after 60 hours annealing at $1300{ }^{\circ} \mathrm{C}$. The explanation of the striking differences between cold and hot implantations is most probably in terms of binding energies. In the latter case the bonding of silicon and carbon to the crystal lattice is strong enough to prevent chemical reactions with iodine, which seems not to be true in the amorphous phase obtained after room temperature implantation.

\section{Conclusion}

As volume diffusion in silicon carbide can safely be neglected at typical operating conditions of HTR's, the transport of radioactive silver and iodine fission products into the primary cooling system will only depend on the grain and mechanical structure of the silicon carbide coatings of fuel kernels. Their diffusion is therefore investigated in layers produced under conditions similar to those pertaining during the coating of fuel particles. Although the fixed position of the substrates in the CVD-reactor is not necessarily leading to identical coatings as on the fluidised parti- 
cles, which sample conditions at different locations in the reactor, we believe that the results are nevertheless representative. The diffusion behaviour observed in this study is of the same order as determined for commercial wafers. Collisions between particles during the coating process seem not to be an important factor in the occurrence of fuel particle failure. Extracted diffusion coefficients below $10^{-20} \mathrm{~m}^{2} \mathrm{~s}^{-1}$ at $1100{ }^{\circ} \mathrm{C}$ for silver and iodine are small enough to prevent any significant contamination of the cooling medium. At the typical maximum temperature of $1000{ }^{\circ} \mathrm{C}$ encountered inside a fuel kernel of a gas-cooled HTR, the diffusion coefficients would be less than $10^{-21} \mathrm{~m}^{2} \mathrm{~s}^{-1}$. The fractional release from fuel particles with intact silicon carbide coatings of typically $35 \mu \mathrm{m}$ thicknesses during their total residence time in the core would be infinitesimal $\left(<<10^{-}\right.$ ${ }^{23}$ /annum). The fact that high silver losses from fuel elements have been reported in the literature must therefore be either due to $\mathrm{SiC}$ coatings with structural imperfections or diffusion enhancing impurities in their grain boundaries. This is apparently not the case for the PBMR coatings. However, one has to bear in mind that the current study makes use of coatings deposited on polycrystalline $\mathrm{SiC}$ substrates. The deposition of $\mathrm{SiC}$ on pyrolithic carbon might introduce stresses parallel to the interface during cooling and heating cycles, which can lead to mechanical imperfections. Finally, this study also indicates that $\mathrm{SiC}$ might not be a suitable cladding material for future HTR's running at operating temperatures significantly above $1100{ }^{\circ} \mathrm{C}$, as irradiation effects of fast neutrons might create favourable conditions for a chemical attack by iodine.

\section{Acknowledgements}

Financial support of the National Research Foundation and the Bundesministerium für Bildung und Forschung is gratefully acknowledged. Thanks are due to Gerald Lenk from the Institut für Festkörperphysik, Friedrich-Schiller-Universität Jena, for the implantations. 


\section{References}

[1] W. Amian, „Experimentelle Untersuchung zum Transportverhalten von Silber in Brennstoffteilchen für Hochtemperaturreaktoren“, KFA-Jülich, Jül-1731, Jülich (1981).

[2] W. Amian, D. Stöver, Nucl. Technol. 61 (1983) 475.

[3] H.J. MacLean, "Silver Transport in CVD Silicon Carbide", Ph.D. Thesis, Massachusetts Institute of Technology, Cambridge (2004).

[4] E. Friedland, J.B. Malherbe, N.G. van der Berg, T. Hlatshwayo, A.J. Botha, E. Wendler, W. Wesch, J. Nucl. Mater. 389 (2009) 326.

[5] W. Jiang, W.J. Weber, V. Shutthanandan, L. Li, S. Thevuthasan, Nucl. Instrum. and Meth. B 219/220 (2004) 642 .

[6] E. Friedland, N.G. van der Berg, J.B. Malherbe, R.J. Kuhudzai, A.J. Botha, E. Wendler, W. Wesch, Nucl. Instrum. and Meth. B 268 (2010) 2892.

[7] A. Audren, A. Benyagoub, L. Thomé, F. Garrido, Nucl. Instrum. and Meth. B 257 (2007) 277.

[8] E. Wendler, A. Heft, W. Wesch, Nucl. Instrum. and Meth. B 141 (1998) 105.

[9] J.F. Ziegler, J.P. Biersack, U. Littmark, “The Stopping and Ranges of Ions in Solids", Pergamon Press, New York (1985).

[10] J.F. Ziegler, “The Stopping and Ranges of Ions in Matter", Pergamon Press, New York (1977).

[11] L.L. Snead, T. Nozawa, Y. Katoh, T.-S. Byun, S. Kondo, D.A. Petti, J. Nucl. Mater. 371 (2007) 329.

[12] N.G. van der Berg, J.B. Malherbe, A.J. Botha, E. Friedland, Surf. Interface Anal. 42 (2010) 1156.

[13] R. Devanathan, W.J. Weber, F. Gao, J. Appl. Phys. 90 (2001) 2303.

[14] S.M. Myers, S.T. Picraux, T.S. Prevender, Phys. Rev. B 9 (1974) 3953.

[15] H. Nabielek, P.E. Brown, P. Offermann., Nucl. Technol. 35 (1977) 483.

[16] H.J. MacLean, R.G. Ballinger, L.E. Kolaya, S.A. Simonson, N. Lewis, M.E. Hanson, J. Nucl. Mater. 357 (2006) 31.

[17].D. Shrader, S.M. Khalil, T. Gerczak, T.R. Allen, A.J. Heim, I. Szlufarska, D. Morgan, J. Nucl. Mater. (2010), doi: 10.1016/j.jnucmat.2010.10.088. 
[18] E. Friedland, N.G. van der Berg, J.B. Malherbe, E. Wendler, W.Wesch, Proceedings of TMS Meeting 2011, San Diego, USA (submitted). 


\section{Figure Captions}

Fig. 1: Sample holder for the CVD coater at PBMR (Pty) Ltd. Substrates of commercial polycrystalline silicon carbide wafers are fixed in grooves between the horizontal rods. An arrow points at one of seven mounted substrates.

Fig. 2: RBS spectra of implanted samples before annealing. Arrows indicate the positions of the surface signals from carbon, silicon and the implants.

Fig. 3: SEM images showing the untreated top surface (left) and a polished and etched cross-section (right) of the deposited silicon carbide layer.

Fig. 4: Depth profiles in PBMR produced CVD-SiC before and after isochronal annealing for silver implants at $600{ }^{\circ} \mathrm{C}$.

Fig. 5: Depth profiles in PBMR produced CVD-SiC before and after isochronal annealing of iodine implants at room temperature and $600{ }^{\circ} \mathrm{C}$.

Fig. 6: Isothermal annealing curves for silver implants displaying the square of the profile widths for three different temperatures.

Fig. 7: Isothermal annealing curves at $1100{ }^{\circ} \mathrm{C}$ and $1200{ }^{\circ} \mathrm{C}$ for room temperature iodine implants displaying the square of the profile widths $(\mathrm{O})$ compared with results for commercial wafers $(\Delta)$ from ref. [6].

Fig. 8: Isothermal annealing curves at $1200{ }^{\circ} \mathrm{C}$ and $1300{ }^{\circ} \mathrm{C}$ for iodine implants at $600{ }^{\circ} \mathrm{C}$ displaying the square of the profile widths $(\mathrm{O})$ compared with results for commercial wafers $(\Delta)$ from ref. [18]'

Fig. 9: Retention fractions as a function of isothermal annealing time. The upper graph displays the results for silver implants at $1200{ }^{\circ} \mathrm{C}, 1300{ }^{\circ} \mathrm{C}$ and $1400{ }^{\circ} \mathrm{C}$, while the lower graph compares the iodine results at $1200{ }^{\circ} \mathrm{C}$ for room temperature implants $(\mathrm{O})$ with those of the commercial samples $(\Delta)$ from ref. [6].

Fig. 10: Experimental silver diffusion coefficients in PBMR-produced CVD-SiC (O). The solid line represents a theoretical fit assuming Arrhenius type temperature dependence. For comparison the results for commercial wafers $(\Delta)$ from ref. [4] are also shown.

Fig. 11: SEM images at different magnifications of PBMR produced CVD-SiC implanted with iodine at room temperature after annealing for 5 hours at $1300{ }^{\circ} \mathrm{C}$.

Fig. 12: SEM images at different magnifications of PBMR produced CVD-SiC implanted with iodine at $600{ }^{\circ} \mathrm{C}$ after annealing for 5 hours at $1300{ }^{\circ} \mathrm{C}$ at different magnifications. 


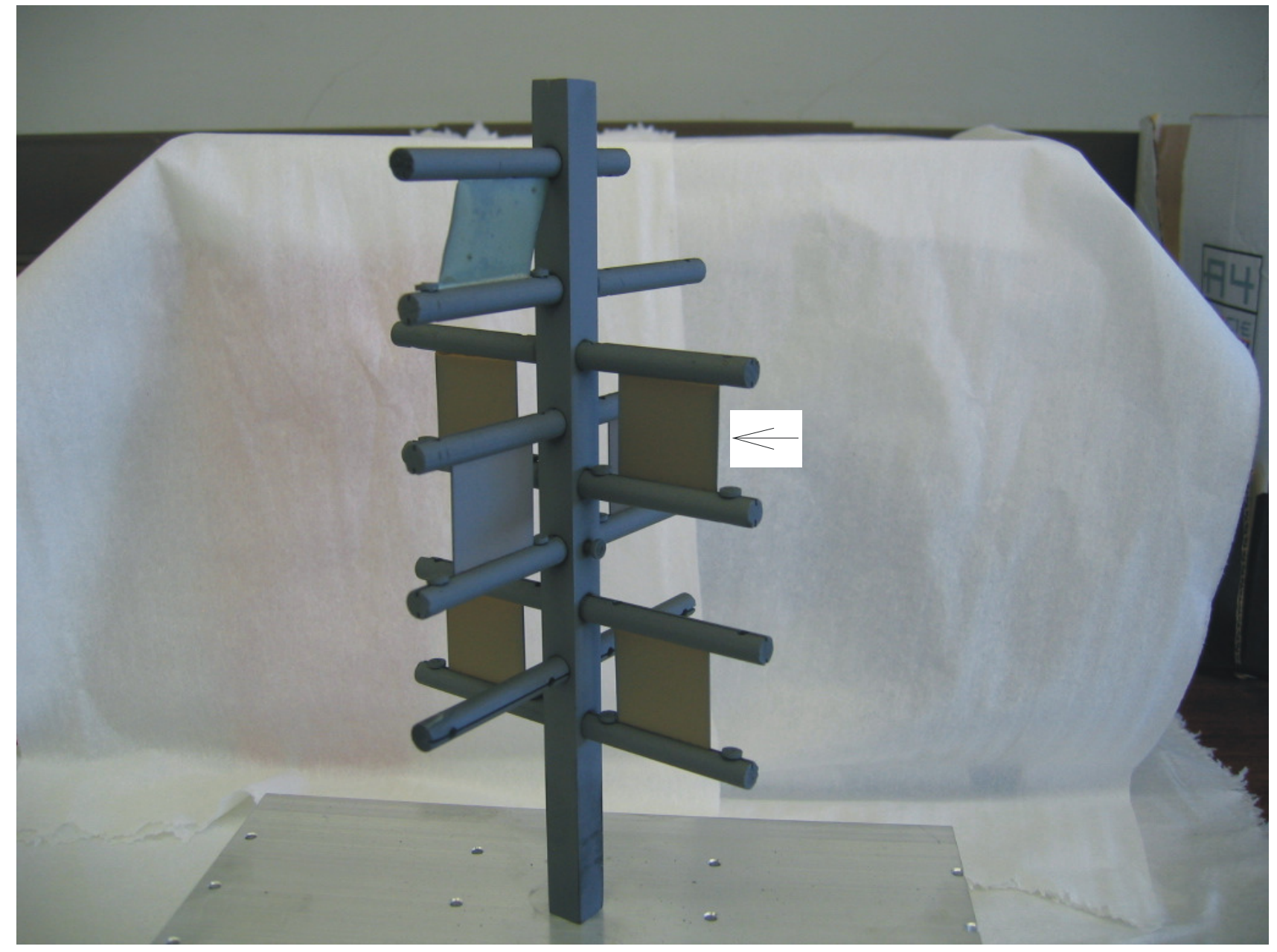

Figure 1 


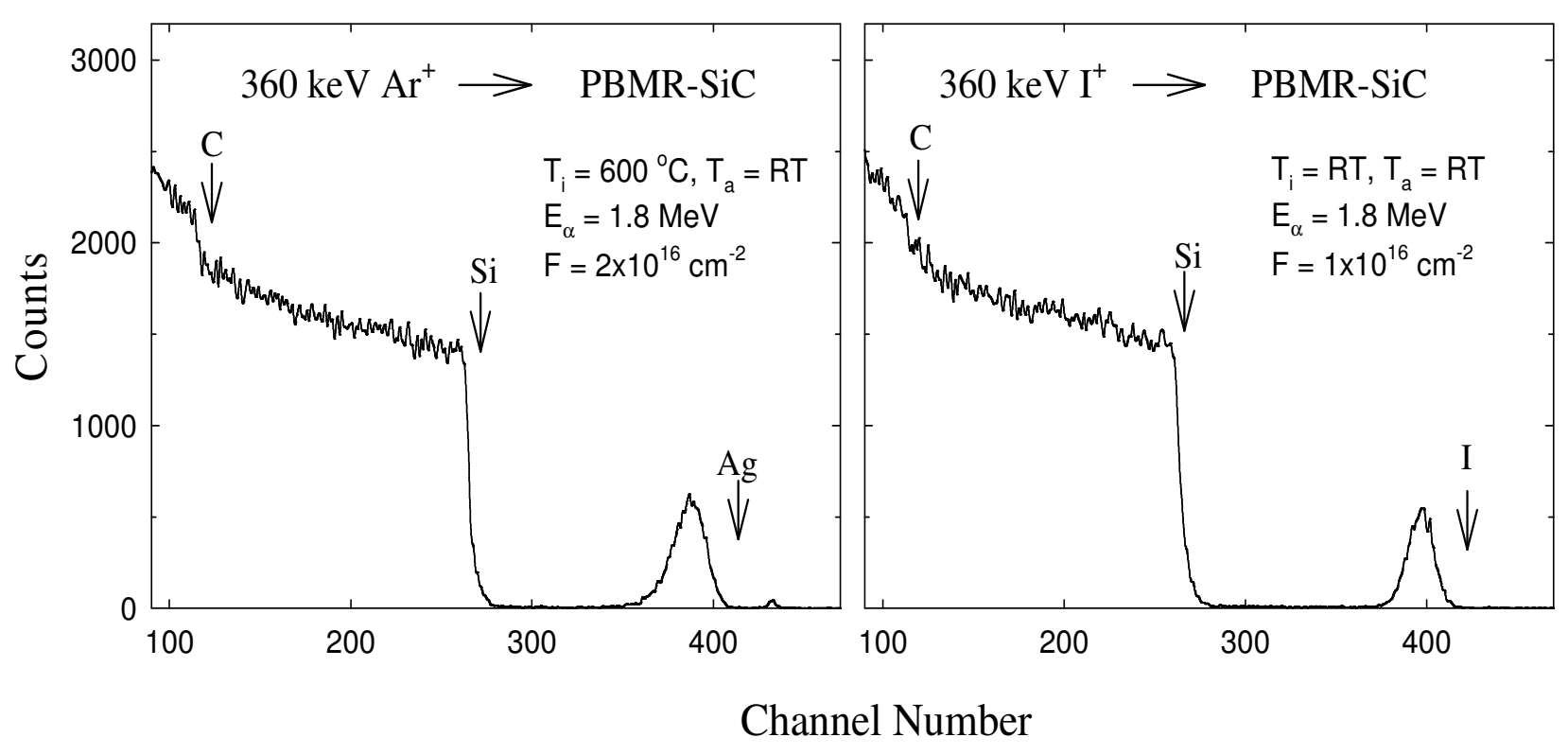

Figure 2 

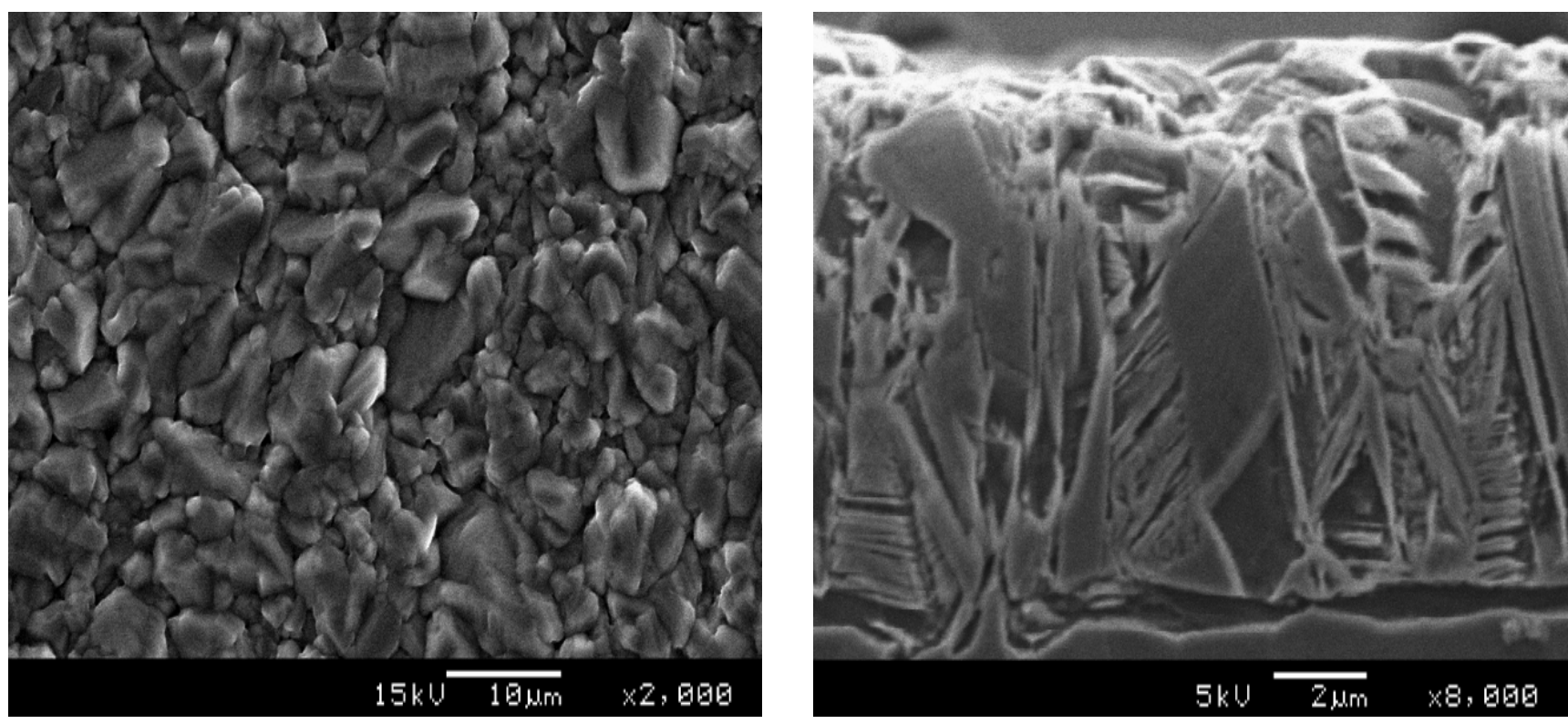

Figure 3 


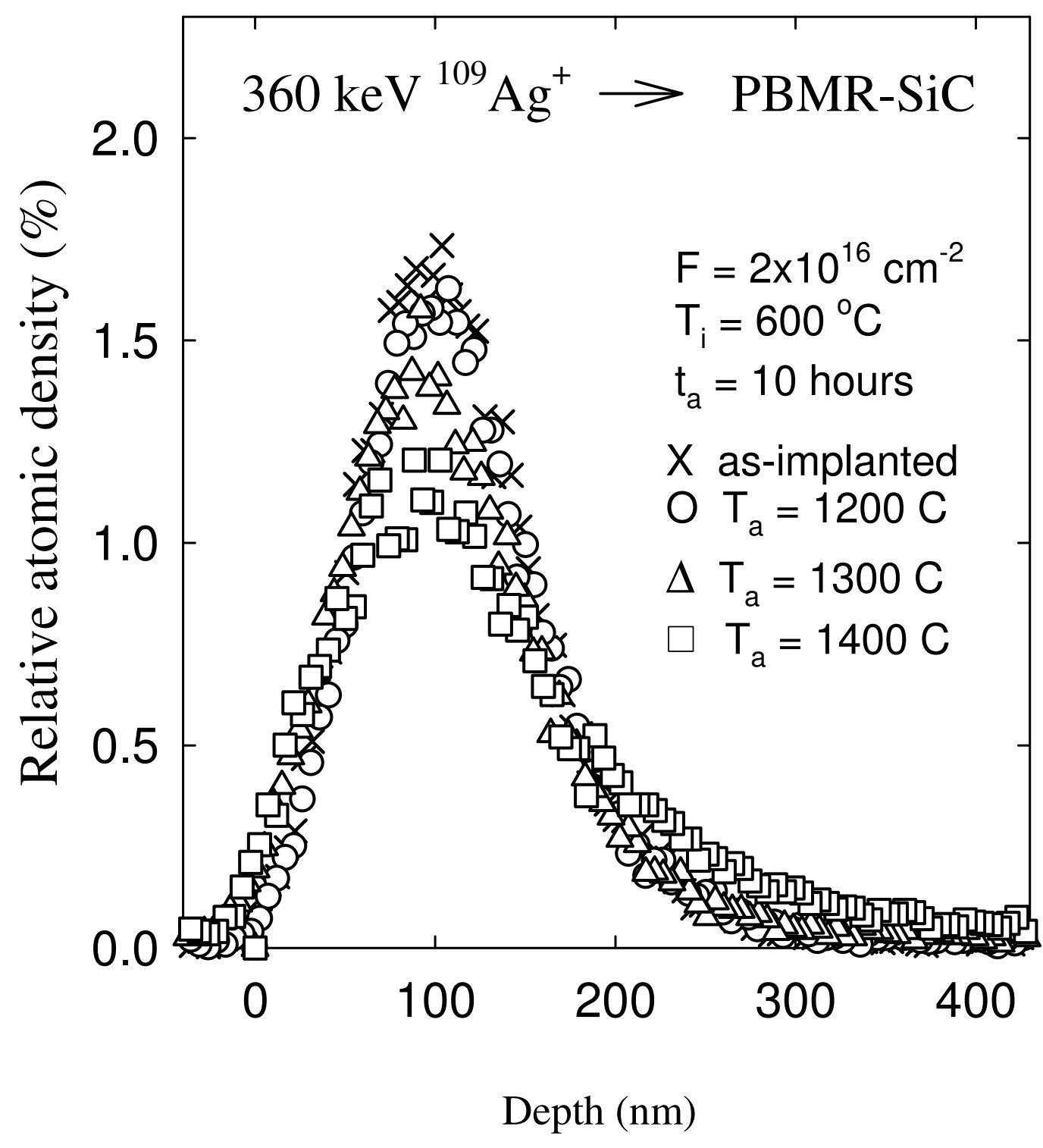

Figure 4 


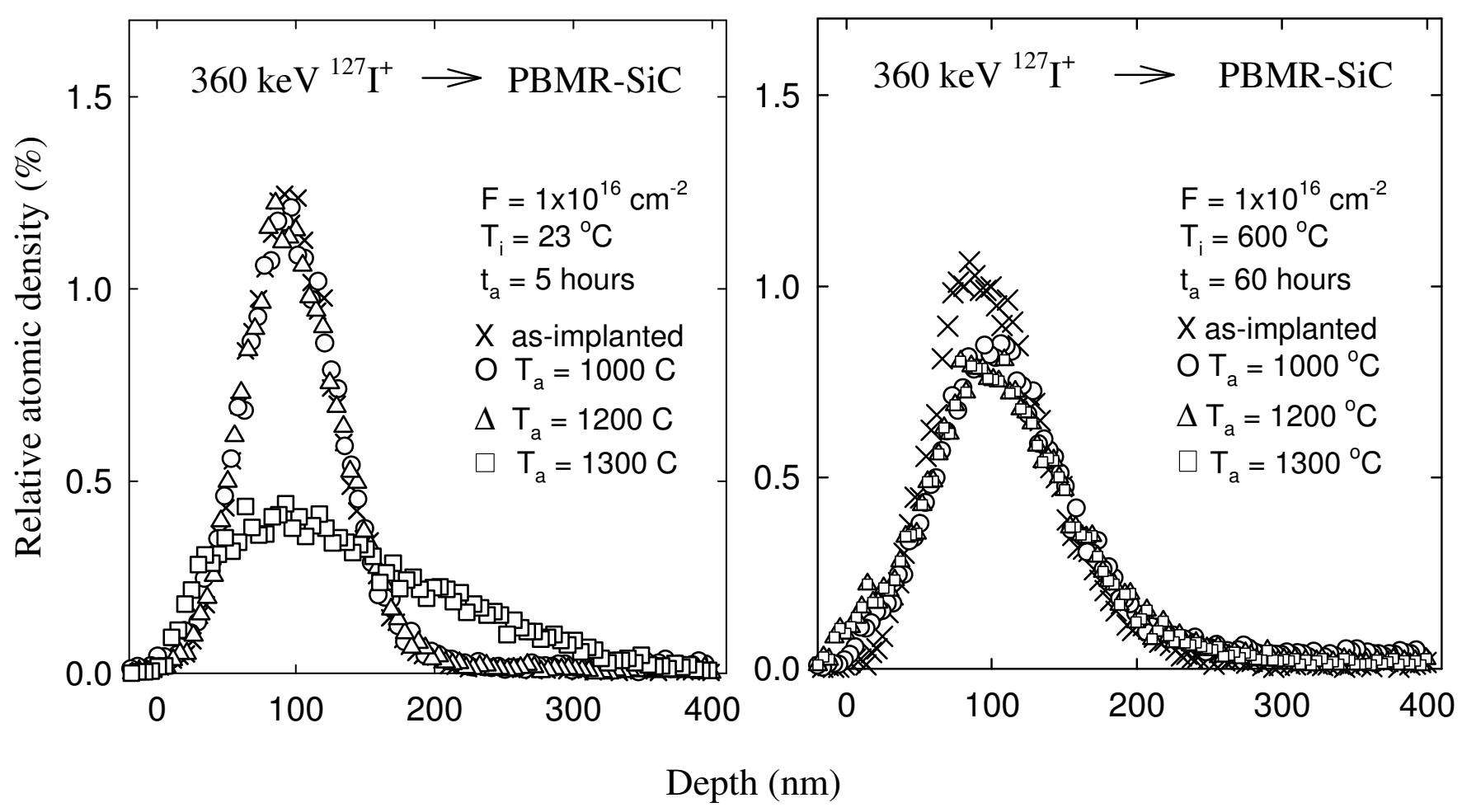

Figure 5 


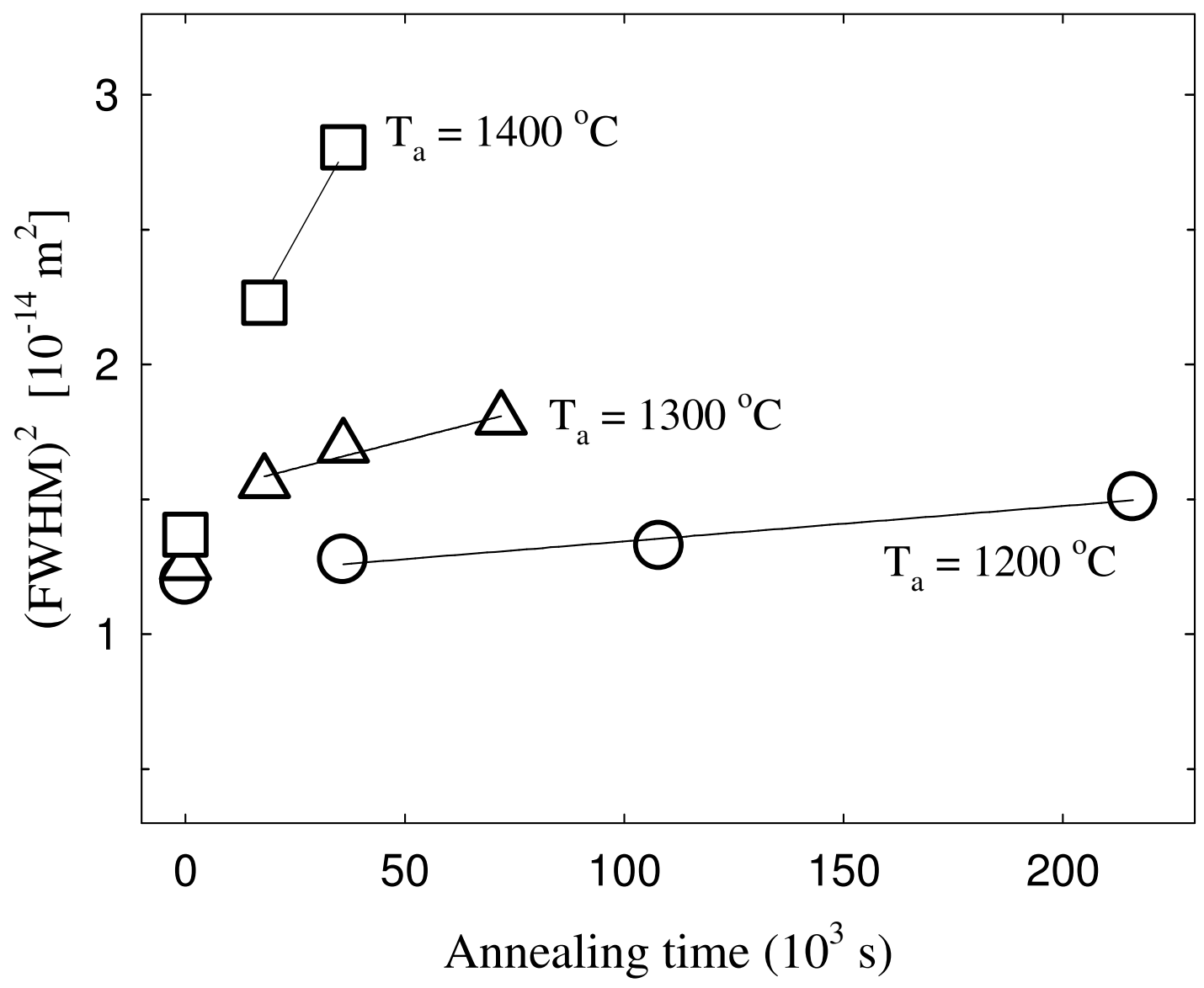

Figure 6 


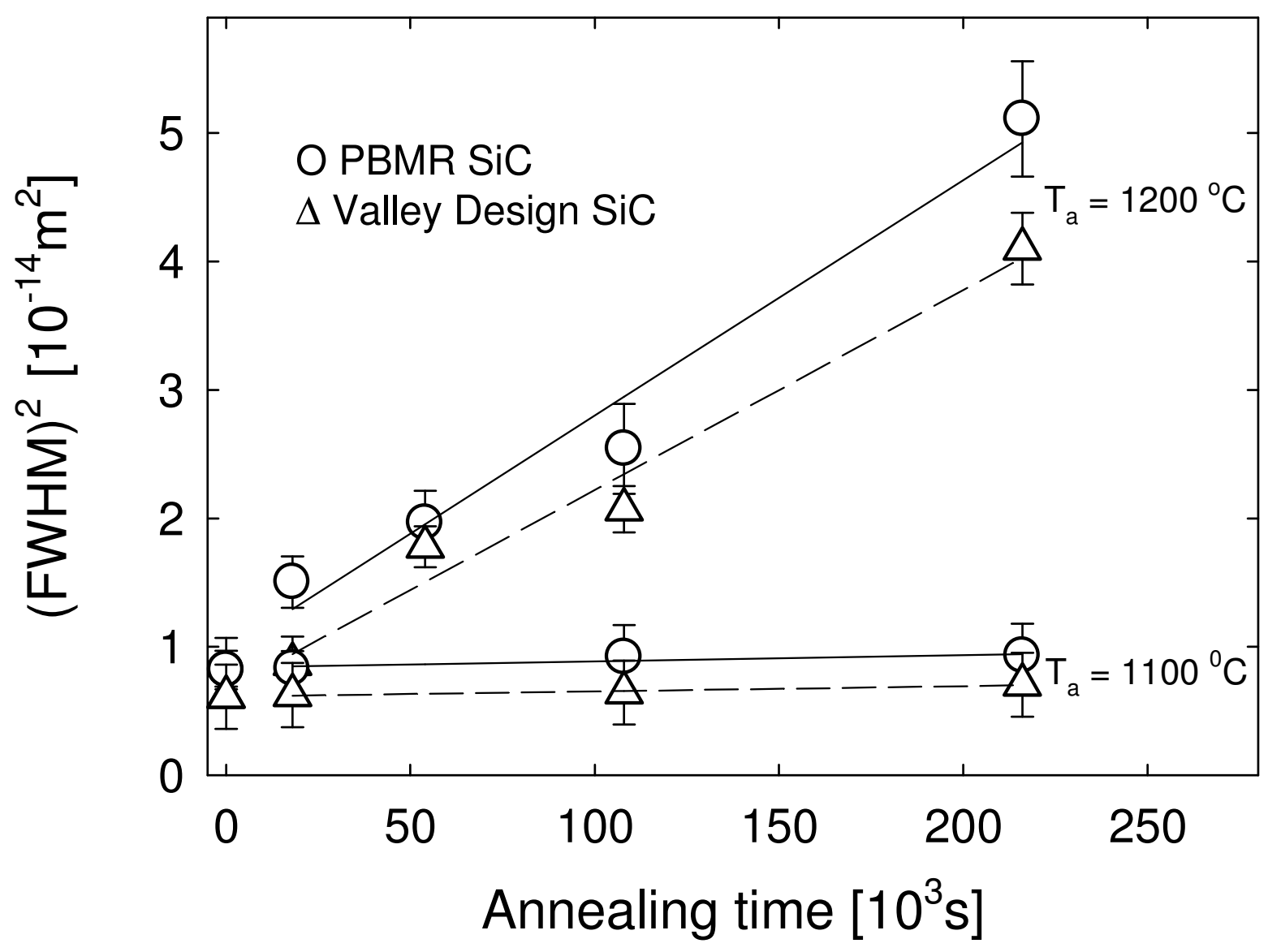

Figure 7 


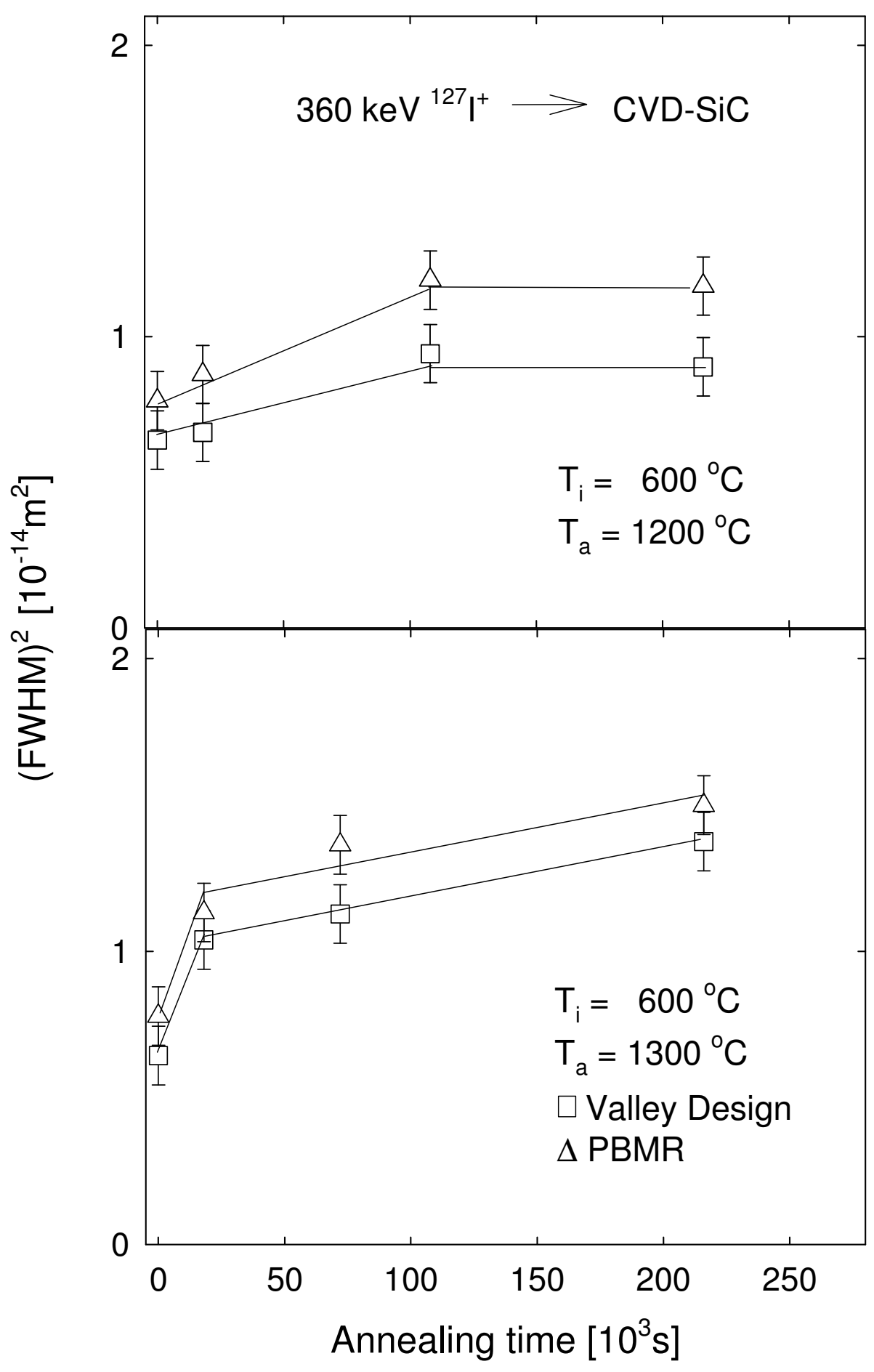

Figure 8 

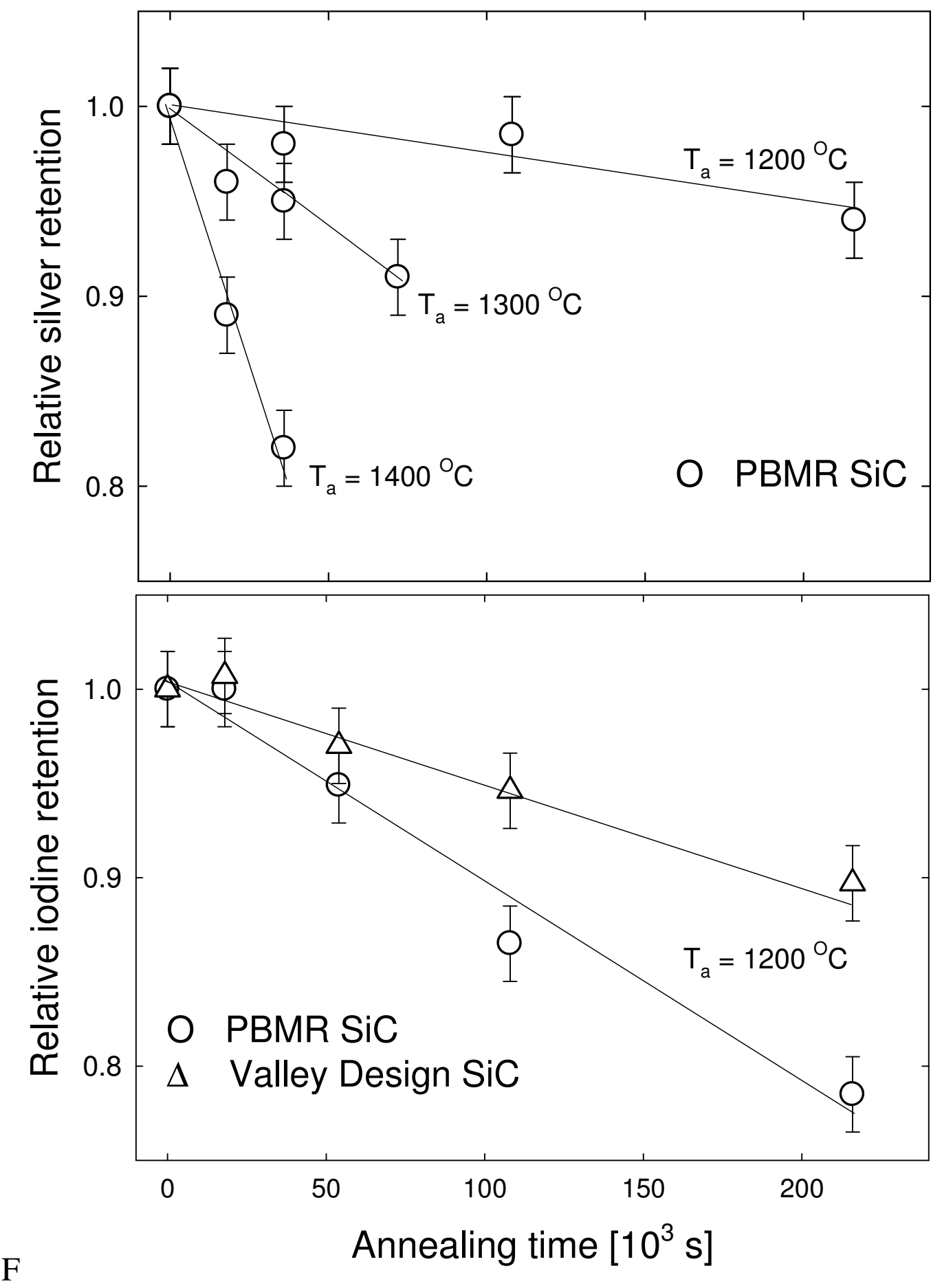

Figure 9 


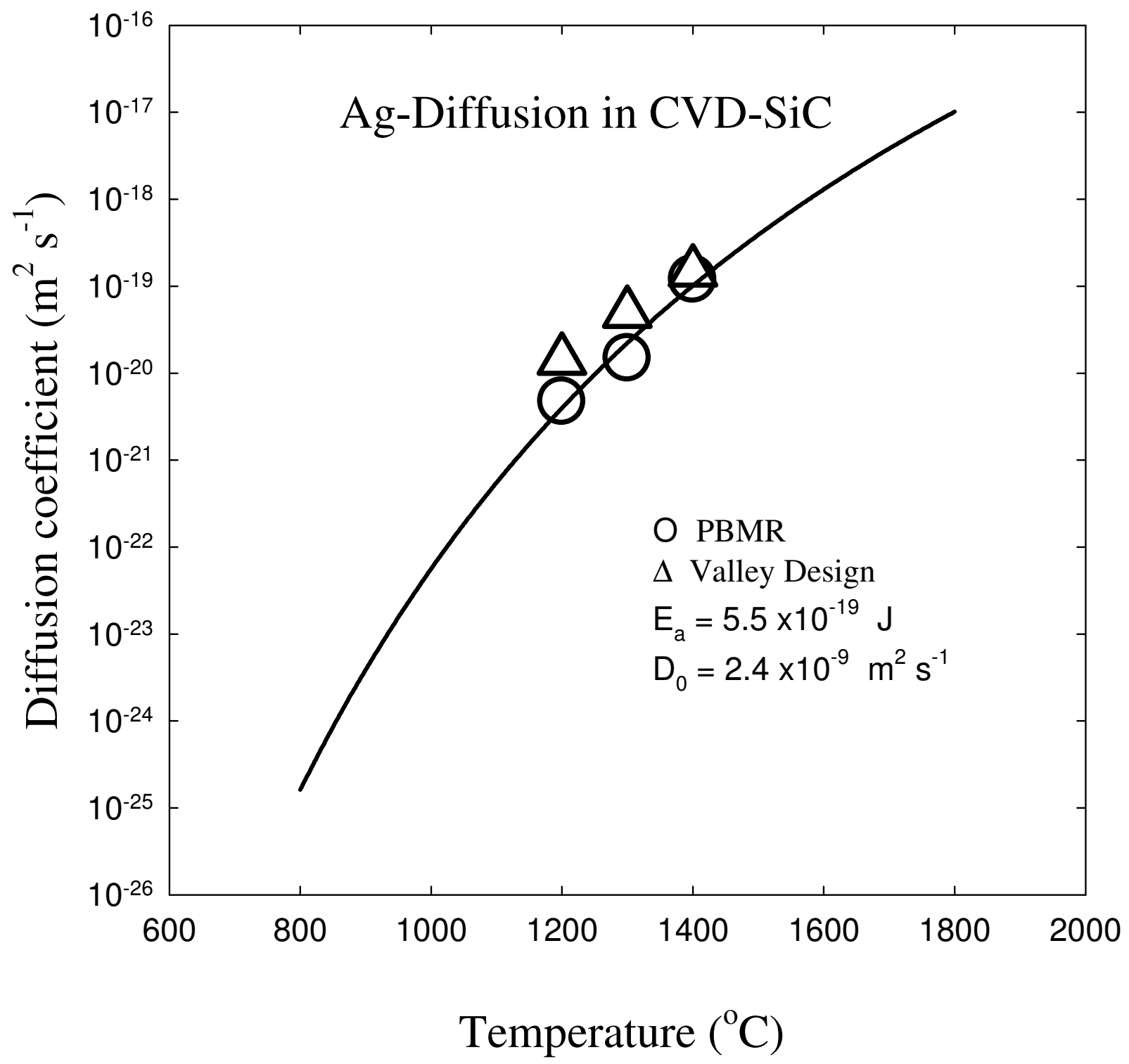

Figure 10 


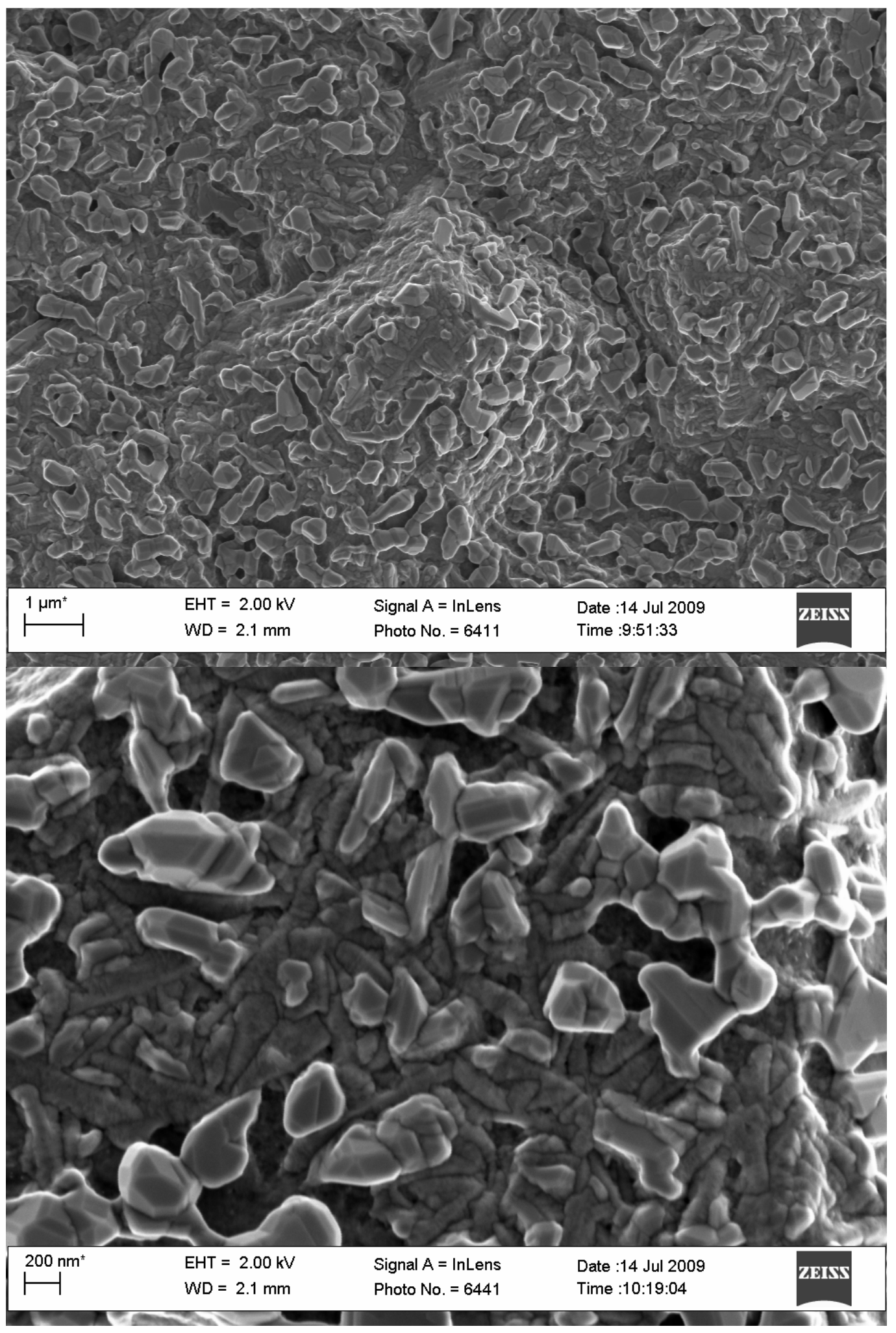

Figure 11 

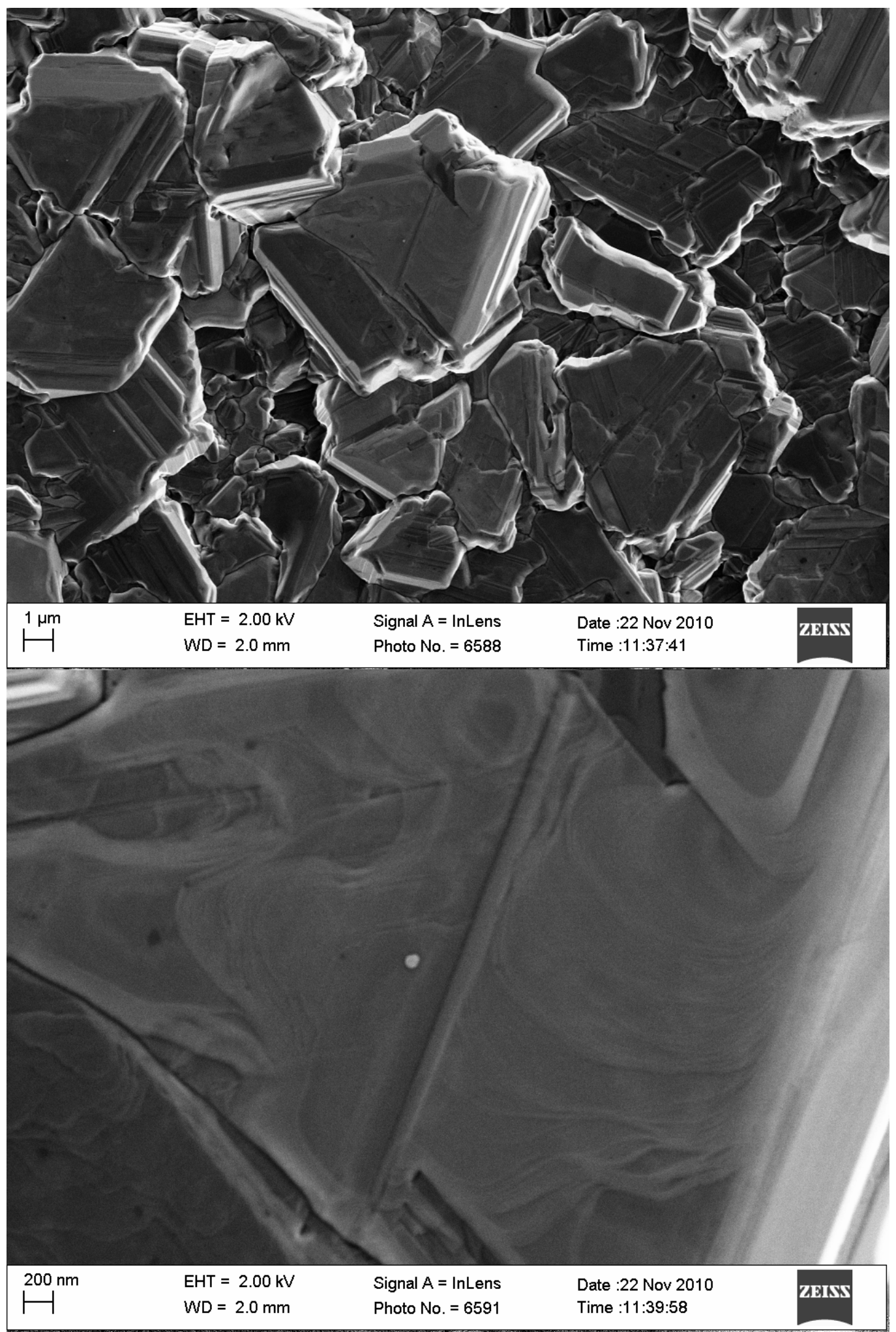

Figure 12 